\title{
Editorial: The Genomics of Biological Invasion
}

\author{
Angela McGaughran ${ }^{1 *}$, Emiliano Mori ${ }^{2}$ and Claudio S. Quilodrán ${ }^{3}$ \\ ${ }^{1}$ Invasomics Laboratory, Te Aka Mātuatua - School of Science, University of Waikato, Hamilton, New Zealand, ${ }^{2}$ Institute of \\ Terrestrial Ecosystems, National Research Council IRET-CNR, Sesto Fiorentino, Italy, ${ }^{3}$ Department of Biology and \\ Biochemistry, University of Fribourg, Fribourg, Switzerland
}

Keywords: biological invasion, genomics, invasive species, invasion success, invasion genomics

\section{Editorial on the Research Topic}

\section{The Genomics of Biological Invasion}

Understanding how invasive species rapidly infiltrate and establish in new areas is critically relevant for ecological management, pest control, climate change adaptation, and evolution (Doherty et al., 2016; Maxwell et al., 2016). Invasive species are almost always detrimental to native flora and fauna: they may out-compete natives in the race for resources, introduce parasites and diseases, and cause immense environmental damage (Clavero and García-Berthou, 2005; Hulme, 2014; Vilcinskas, 2015).

Invasion success often reflects a life history trade-off for the invading organism. Free from predators (i.e., enemy release) or toxins in the new environment, the invasive species can limit investment in defense or tolerance traits and allocate more energy toward growth and reproduction (Heger and Jeschke, 2018). Therefore, invasion is often seen as a fundamentally demographic process (National Research Council, 2002; Duncan et al., 2014). However, for a species to become

OPEN ACCESS

Edited and reviewed by: Lynne Beaty,

Penn State Erie, The Behrend College, United States

*Correspondence: Angela McGaughran ang.mcgaughran@gmail.com

Specialty section: This article was submitted to

Population, Community, and Ecosystem Dynamics, a section of the journal Frontiers in Ecology and Evolution

Received: 08 November 2021 Accepted: 08 December 2021 Published: 23 December 2021

Citation:

McGaughran A, Mori E and Quilodrán CS (2021) Editorial: The Genomics of Biological Invasion.

Front. Ecol. Evol. 9:810817. doi: 10.3389/fevo.2021.810817 invasive, it must tolerate or adapt to the environmental and ecological characteristics of the invaded habitat, in which it did not evolve and to which it may be poorly matched (Prentis et al., 2008). Thus, the success of invasive populations is likely also underpinned by adaptive genomic characteristics, such as those leading to insecticide resistance (Franck et al., 2007) or expansions in host breadth (Pearce et al., 2017).

Advances in genomic technologies allow us to better understand the role of the genome in invasion. The present special topic, entitled The Genomics of Biological Invasion, aimed to include research papers that used genomic data to understand various aspects of invasion success. With this broad scope, our special issue features research on a number of different study systems (the green crab, Carcinus maenas; the knapweed, Centaurea diffusa; the Pacific oyster, Crassostrea gigas; and the "pavement" ant, Tetramorium immigrans), and includes a simulation-based study, an opinion, and a review.

Burgess et al. focus their review on invasive mammalian species in island systems, which have experienced particularly high rates of invasive-driven biodiversity loss (Bellard et al., 2016). They evaluate current management of invasive mammals on islands and comprehensively summarize the role genomic methods can play. Of particular note, Burgess et al. identify the utility of genomics in eradication and biosecurity protocols, noting environmental DNA (eDNA) and genome editing as important emerging tools. Focusing on analytical tools, Rius and Turon assess the assumptions and applicability of phylogeography to invasion genomics. This is important because phylogeography research aims to understand the relationship between geography and genotype, and invasive species distributions are changing as they undergo geographic range expansion in the face of increased global trade and movement, and warming temperatures (Hulme, 2017, 2021; Robinson et al., 2020; Nerva et al., 2021). However, in the case of recent 
introductions yet to achieve mutation-migration-drift equilibrium, phylogeographic analyses may not be appropriate. Instead, Rius and Turon champion the use of temporal samples (e.g., museum collections) in invasion research, alongside a careful application of phylogeographic approaches and interpretation of results.

Genetic tools have been used to answer a variety of questions related to biological invasions in new habitats, spanning the invasion sequence from pre- to post-introduction to obtain insights into incursion pathways, adaptation, and demography (Barrett, 2015; North et al., 2021). Using spatially explicit simulations to examine structured populations with a low to moderate amount of hybridization, Quilodrán et al. show that the distance of the invasive taxon from the source of the original invasion influences the degree of introgression at neutral loci. This spatial heterogeneity is consistent with empirical data (Nussberger et al., 2018; Oswald et al., 2019) and may explain spatial patterns of Neanderthal introgression into modern humans following their out-of-Africa expansion (Quilodrán et al.). Zhang et al. further demonstrate the utility of genomic data in understanding the population structure and incursion pathways associated with a biological invasion. They use a citizen-science approach to analyse the invasion of the urban "pavement" ant (T. immigrans), which is ubiquitous in pavement and other human-modified habitats. Using 78 samples and a reduced representation sequencing approach (ddRADseq), Zhang et al. find weak population structure and low genetic diversity consistent with the original incursion including one, or a few, genetically similar colonies.

Focusing on post-introduction adaptation, Tepolt and Palumbi collected samples of a widespread invasive marine crab (C. maena) from six populations, which provided parallel thermal gradients in invasive and native ranges. Using a combination of genomic and phenotypic data, they identify candidate genetic markers that align with differences in thermal phenotypes across populations. Around $70 \%$ of these markers fall into a genomic cluster, exemplifying the putative role of genomic islands of divergence in facilitating rapid temperature adaptation in invasive species. Turner et al. also take a combined genomic and phenotypic approach to examine differences between invasive

\section{REFERENCES}

Barrett, S. C. (2015). Foundations of invasion genetics: the baker and stebbins legacy. Mol. Ecol. 24, 1927-1941. doi: 10.1111/mec.13014

Bellard, C., Cassey, P., and Blackburn, T. M. (2016). Alien species as a driver of recent extinctions. Biol. Lett. 12:20150623. doi: 10.1098/rsbl.2015.0623

Clavero, M., and García-Berthou, E. (2005). Invasive species are a leading cause of animal extinctions. Trends Ecol. Evol. 20:110. doi: 10.1016/j.tree.2005.01.003

Doherty, T. S., Glen, A. S., Nimmo, D. G., Ritchie, E. G., and Dickman, C. R. (2016). Invasive predators and global biodiversity loss. Proc. Natl. Acad. Sci. U.S.A. 113, 11261-11265. doi: 10.1073/pnas.1602480113

Duncan, R. P., Blackburn, T. M., Rossinelli, S., and Bacher, S. (2014). Quantifying invasion risk: the relationship between establishment probability and founding population size. Methods Ecol. Evol. 5, 1255-1263. doi: $10.1111 / 2041-210 X .12288$ and native populations. They generate genomic resources (a draft reference genome and a plastome assembly) in the nonmodel knapweed (C. diffusa), and phenotype 372 individuals from invasive/native populations in a common environment. Identifying differences in leaf width that correlate with fitness and that vary between invasive and native counterparts, Turner et al. demonstrate a mechanistic pathway for adaptation in this invasive plant, while also identifying candidate genes underlying the genetic architecture of the leaf width trait. Finally, Wegner et al. combine genomic and transcriptomic data to identify both plastic (i.e., immediate physiological) and selective (i.e., longer-term adaptation) aspects of survival in novel invaded environments in the Pacific oyster (C. gigas). Their approach shows that different candidate loci are generally important across the two time-scales. However, in a small number of cases, they identify overlaps between the temporal datasets that provide new insights into the mechanisms underlying rapid environmental tolerance and adaptation during invasion.

Collectively, our special topic highlights the applicability of genomic tools to a variety of study systems and analytical approaches in both basic and applied aspects of invasion. It further demonstrates the specific utility of combining genomic data with other data types to elucidate mechanistic processes that facilitate invasion success.

\section{AUTHOR CONTRIBUTIONS}

AM proposed the special topic and wrote the first draft of the manuscript. All authors contributed to manuscript revision and read and approved the submitted version.

\section{FUNDING}

CSQ acknowledges support from the Swiss National Science Foundation ( $\mathrm{N}^{\circ}$ P400PB_183930 and P5R5PB_203169).

\section{ACKNOWLEDGMENTS}

The editors would like to thank all the authors and reviewers who participated in the Research Topic. 
Maxwell, S. L., Fuller, R. A., Brooks, T. M., and Watson, J. E. (2016). Biodiversity: the ravages of guns, nets and bulldozers. Nature 536, 143-145. doi: $10.1038 / 536143 a$

National Research Council (2002). Predicting Invasions of Nonindigenous Plants and Plant Pests. Washington, DC: The National Academies Press.

Nerva, L., Iannucci, A., Menchetti, M., Andreoni, A., Chitarra, W., Martini, M., et al. (2021). Where do chip and dale come from? origins of invasive populations of the siberian chipmunk in Europe. Mammal Res. 66, 525-529. doi: $10.1007 /$ s13364-021-00569-4

North, H. L., McGaughran, A., and Jiggins, C. (2021). Insights into invasive species from whole-genome resequencing. Mole. Ecol. 30, 6289-6308. doi: $10.1111 / \mathrm{mec} .15999$

Nussberger, B., Currat, M., Quilodran, C. S., Ponta, N., and Keller, L. F. (2018). Range expansion as an explanation for introgression in European wildcats. Biol. Conserv. 218, 49-56. doi: 10.1016/j.biocon.2017.1 2.009

Oswald, J. A., Harvey, M. G., Remsen, R. C., Foxworth, D. U., Dittmann, D. L., Cardiff, S. W., et al. (2019). Evolutionary dynamics of hybridization and introgression following the recent colonization of glossy ibis (Aves: Plegadis Falcinellus) into the New World. Mole. Ecol. 28, 1675-1691. doi: 10.1111/mec.1 5008

Pearce, S. L., Clarke, D. F., East, P. D., Elfekih, S., and Gordon, K. H. J., Jermiin, L. S., et al. (2017). Genomic innovations, transcriptional plasticity and gene loss underlying the evolution and divergence of two highly polyphagous and invasive Helicoverpa pest species. BMC Biol. 15:63. doi: 10.1186/s12915-017-0 402-6
Prentis, P. J., Wilson, J. R., Dormontt, E. E., Richardson, D. M., and Lowe, A. J. (2008). Adaptive evolution in invasive species. Trends Plant Sci. 13, 288-294. doi: 10.1016/j.tplants.2008.03.004

Robinson, T. B., Martin, N., Loureiro, T. G., Matikinca, P., and Robertson, M. P. (2020). Double trouble: the implications of climate change for biological invasions. NeoBiota 62, 463-487. doi: 10.3897/neobiota.62.55729

Vilcinskas, A. (2015). Pathogens as biological weapons of invasive species. PLOS Pathogens 11:e1004714. doi: 10.1371/journal.ppat.1004714

Conflict of Interest: The authors declare that the research was conducted in the absence of any commercial or financial relationships that could be construed as a potential conflict of interest.

Publisher's Note: All claims expressed in this article are solely those of the authors and do not necessarily represent those of their affiliated organizations, or those of the publisher, the editors and the reviewers. Any product that may be evaluated in this article, or claim that may be made by its manufacturer, is not guaranteed or endorsed by the publisher.

Copyright (๑) 2021 McGaughran, Mori and Quilodrán. This is an open-access article distributed under the terms of the Creative Commons Attribution License (CC BY). The use, distribution or reproduction in other forums is permitted, provided the original author(s) and the copyright owner(s) are credited and that the original publication in this journal is cited, in accordance with accepted academic practice. No use, distribution or reproduction is permitted which does not comply with these terms. 